code into language, must always form a very important element in the commercial value of all high-speed arrangements, when the speed is beyond that of the public requirements of the circuit.

Alexander Bain's chemical printing telegraph, invented in 18.16 , of which this American automatic machine is only a modernised adaptation, is shown at Fig. 25. It combined methods of arranging, transmitting, and receiving electrical telegraph communications, in which mechanically-composed communications were transmitted through electric circuits, and received by chemically prepared surfaces, both apparatus being kept in motion by mechanical means, without the aid of magnets. The apparatus consisted of a frame containing a driving power by which, a rotatory motion was imparted to the metal drum $B$, placed in connection with the earth by means of the contact springs $\mathrm{E} E$. The paper strip P P, chemically prepared by being immersed in a solution of sulphuric acid and prussiate of potass to receive the sequence of currents transmitted through the wire from the "transmitter," is wound upon the drum A, and is drawn forward over the revolving earth contact $B$ at a uniform speed by reason of the pressure of the break roller $M$, which may, whenever the paper is not required to advance, be withdrawn by the lever $\mathrm{H}$ working on the centre $\mathrm{R}$, and kept in position either way by the action of the spring roller $w$. An insulated metallic style $D$, in connection with the line wire $f$, and furnished with the nccessary screw adjustments $a, b, c$, is arranged to press uniformly upon the chenically-prepared paper as it passes over the earth drum B. The style $D$ can also be removed from pressing contact with the paper ribbon when required, as indicated by the dotted outline. When therefore the style D is passing over the surface of the prepared paper, and electric currents are passed through the line wire $f$ from the distant station, the electric circuit will be completed through the paper ribbon $\mathrm{P}$, and the metallic drum $\mathrm{E}$, with the earth $\mathrm{E}$, and in the passage of the current, the iron in the chemical solution is decomposed and a dark blue mark becomes visible upon the paper corresponding in length to the duration of the current; so that if the Jacquard ribbon at the distant station is perforated into the necessary length of holes to represent the sequences of dots and dashes in the Morse code, to form letters and words, the chemical decomposition from the style D will be an accurate replica of the distant message in the "dot" and "dash" symbols. It was thus that in I846 Alexander Bain, the clever and ingenious Edinburgh watchmaker, originated a system of electric automatic chemical Jacquard printing, which even at the present day is scarcely understood, and which in all probability is left to American skill to develop. Its extreme simplicity and wonderful chemical sensibility speak volumes in its favour, provided, as has been already observed, such extreme velocities can be profitably worked in this small planet of ours.

$$
\text { (To be continued.) }
$$

\section{RECENT FRENCH MATHEMATICAL PUBLICATIONS}

N CHASLES is reprinting a new edition of his cele$\mathrm{VI}$. brated work, "Aperçu Historique :" the first part has been already issued. The learned geometer has made no alteration in the book, which was written many years ago and long before he had been led to assert frivolous claims in favour of Pascal, and no allusion is made to the Newton forgeries. The whole work will cost no more than 205., only one-fourth of the selling price of the old edition, which has for some time been very scarce.

There has been in France a revival of interest in the subject of imaginary quantities. Thus, a translation by Laisant of Bellavitis's "Calcul des Equipollences" has been published lately. It is regarded by Bellavitis himself as a system of quaternions in one plane, and thus is somewhat analogous to the efforts made in England to popularise the great Hamilton's theories. But it is only a partial effort, as Bellavitis's results do not admit of being generalised so as to apply to solid geometry.

M. Houiel, whose name is connected with the publication of a series of useful tables, will very likely be more successful in this respect, as he is preparing a "Theory of Quaternions."

The same mathematician has edited a reprint of a work on the "Geometrical Representation of Imaginary Quantities," originally published in 1806 by Argand. One of his objects appears to have been to defend the rights of his illustrious countryman. But they are not so disregarded in England as the author seems to suppose.

The third and concluding part of the new edition of Briot and Bouquet's "Theory of Elliptic Functions" has appeared. It is quite a new book, though professing to be a second edition of the small octavo volume which became rapidly so popular amongst mathematicians.

M. Paul de Saint Robert has published a third and concluding volume of his interesting "Memoirs," several of which were published in English in the Philosophical Magazine. Amongst these valuable papers, which are here reprinted, we must not neglect to notice the "New formula for determining the altitude from barometric observations." "These formulae embody the results of the observations taken by Mr. James Glaisher in some of his aëronautical ascents. M. Saint Robert in this way improves the well-known Laplace's formulæ, which were based only on the Ramont's observations taken in the Pyrenean ranges; and takes into account the carefully observed facts which had been neglected in England.

\section{NOTES}

THE Committee on the Loan Exhibition of Scientific Apparatus met in the Science Schools at the South Kensington Museum yesterday. It has been determined to postpone the exhibition till March 1876 , and from the strength of the Committee appointed and the interest taken in the scheme by scientific societies, we may expect the collection to be unique.

IT will be of interest to geologists to know that Capt. Feil. den, R.A., the naturalist of the senior ship of the Arctic Expedition, in addition to making the observations on the birds of Northern Europe, Malta, India, China, and North America, which will be found scattered through the pages of the "Zoologist" and quoted by Prof. Newton and Messrs. Sharpe and Dresser in various works, has given much attention to the palæonto'ogy of many of these countries, especially to the Miocenes of Malta and the Faroe islands, and the Mastodon beds of South Carolina. By permission of Prof. Ramsay, V.P.R.S., the Director-General of H.M. Geological Survey, Capt. Feilden has also recently been shown the method employed in carrying out geological field-work by that Survey, by one of its staff, Mr. De Rance.

THE French Academy of Sciences, at its sitting on Monday last, received the report of $\mathrm{M}$. Fleuriais, the head of the Transit of Venus Expedition to Pekin. The observations were very satis* factory indeed, the four contacts having been photographed with complete success. The weather was very boisterous all the day long, but at the four important moments the observers were favoured by a total absence of clouds. They succeeded in executing a map of Pekin, in spite of the obstacles placed in their way by the natives. The dimensions are 8,000 metres by 7,000 , and the length of the walls is 33 kilometres. The instruments set up by the misslonaries last century are in perfect 